JITA: JH. Digital Preservation.

\title{
A INICIATIVA LEGATUM E A PRESERVAÇÃ̃ DIGITAL DE ARQUIVOS AUDIOVISUAIS PÚBLICOS
}

\author{
THE LEGATUM INITIATIVE AND DIGITAL PRESERVATION \\ OF AUDIOVISUAL PUBLIC ARCHIVES \\ LA INICIATIVA LEGATUM Y LA PRESERVACIÓN DIGITAL \\ DE ARCHIVOS AUDIOVISUALES PÚBLICOS
}

\author{
Rubens Ribeiro Gonçalves da Silva ${ }^{1}$ \\ Adriana Lúcia Cox Hollós ${ }^{2}$ \\ Ricardo Sodré Andrade ${ }^{3}$ \\ Neiva Pavezi ${ }^{4}$
}

\section{RESUMO}

Apresenta o percurso e os resultados parciais de pesquisa científica sobre preservação digital de arquivos audiovisuais públicos, cujo principal produto é um modelo de repositório aberto, multi-idiomas e colaborativo Legatum - baseado em uma plataforma digital em conformidade com normas arquivísticas. Ainda em desenvolvimento, esta iniciativa constitui-se em uma série de ações coordenadas ao redor de um repositório digital para o armazenamento e acesso remoto a objetos nascidos digitais ou digitalizados a partir de acervos analógicos audiovisuais públicos de instituições brasileiras e de outros países de idiomas de origem latina.

PALAVRAS-CHAVE: Patrimônio audiovisual. Salvaguarda. Preservação audiovisual. Preservação digital.

Repositório digital.

\section{ABSTRACT}

It presents some partial results of a scientific research on digital preservation of public audiovisual archives, whose primary product is an open, multilingual, collaborative repository model - Legatum - based on a digital platform according compatible with international archival standards. Still in development, this initiative consists of a series of coordinated actions around a digital repository for storage and remote access to born digital objects or digitized ones, from analog audiovisual collections of public institutions in Brazil and other countries of Latin languages

KEYWORDS: Audiovisual Heritage. Audiovisual Safeguarding. Audiovisual Preservation. Digital Preservation. Digital Repository.

\section{RESUMEN}

Presenta la ruta y los resultados parciales de la investigación científica sobre preservación digital de archivos audiovisuales públicos, cuyo principal producto es un modelo de repositorio abierto, multi-idiomas y colaborativo - Legatum - basado en una plataforma digital de acuerdo con las normas archivísticas. Todavía en desarrollo, esta iniciativa consiste en una serie de acciones coordinadas al derredor de un repositorio digital para

${ }^{1}$ Doutor em Ciência da Informação (IBICT). Professor Titular da Universidade Federal da Bahia (UFBA). Bahia, BA. Email: rubensri@ufba.br. ORDID: http://orcid.org/0000-0002-9148-8560.

${ }^{2}$ Doutora em Ciência da Informação (IBCT). Professora do Museu de Astronomia e Ciências Afins - MAST.

Rio de Janeiro, RJ. Email: ahollos@gmail.com.

${ }^{3}$ Doutor em Informação e Comunicação em Plataformas Digitais (Universidade do Porto e Universidade de Aveiro). Mestre em Ciência da Informação (UFBA). Salvador, BA. Email: rsandrade@ufba.br.

${ }^{4}$ Mestre em Patrimônio Cultural (UFSM). Arquivista da Universidade Federal de Santa Maria. Santa Maria, RS. Email: neivapavezi@gmail.com

Submetido em: 17/07/2016 - Aceito em: 14/09/2016. 
el almacenamiento y acceso remoto a objetos nacidos digitales o digitalizados nacidos a partir de colecciones audiovisuales analógicos públicos de instituciones en Brasil y otros países de lenguas de origen latino.

PALABRAS ClAVE: Patrimonio audiovisual. Salvaguardia. Preservación audiovisual. Preservación digital.

Repositorio digital

\section{INTRODUÇÃ̃}

Sem testamento ou, resolvendo a metáfora, sem tradição - que selecione e nomeie, que transmita e preserve, que indique onde se encontram os tesouros e qual o seu valor - parece não haver nenhuma continuidade consciente no tempo, e portanto, humanamente falando, nem passado nem futuro (...).

(Hannah Arendt, 2005, p.3)

Essa passagem de Hannah Arendt inspira a ideia de que haverá uma lacuna na memória social como consequência do uso das tecnologias digitais para a produção da informação contemporânea, seja ela escrita ou audiovisual. O pressuposto é que, para minimizá-la, há que se recriar uma tradição na área dos arquivos que permita uma "continuidade consciente no tempo" por meio de pesquisas científicas para o desenvolvimento de soluções que venham assegurar a salvaguarda do legado digital contemporâneo para as gerações futuras.

No contexto audiovisual contemporâneo, vídeos, áudio, filmes e documentação correlata tem sido produzidos quase totalmente já em meio digital. Essa informação codificada em bits e bytes se desterritorializou de seus suportes analógicos fazendo com que os processos de criação, circulação e fruição dos conteúdos tenham se instaurado de modo fluido e quase onipresente em todas as esferas da sociedade. Esta digitalização da sociedade criou novos espaços, tempos e movimentos que passam a exigir novas estratégias de ação para gerir e manter tais informações digitais usáveis e compreensíveis pelo máximo de tempo possível.

Para Lévy,

o conhecimento e a informação não são imateriais, e sim, desterritorializados; longe de estarem presos a um suporte privilegiado, eles podem viajar. Mas a informação e o conhecimento tão pouco são materiais. A alternativa do material e imaterial vale apenas para substâncias, coisas, ao passo, que a informação e o conhecimento são da ordem do acontecimento ou do processo. (1996, p.56)

Levy vem reforçar o conceito de informação que utilizamos no âmbito desse artigo e das ações de pesquisa do Grupo CRIDI e que decorre do entendimento de que o acesso à informação possibilita a "ampliação de consciência" (SILVA, 2002; 2006 e SZABÓ, 2006; 
2007; 2007a) do indivíduo ou da sociedade que passam a ser capazes de agir no mundo e por ele.

Tal entendimento tem sua origem no conceito presente em nossa teoria original (SILVA, 2002) que propõe que a informação seja vista como um processo que possibilita a expansão de uma consciência relacionada ao reconhecimento da sua própria existência e capacidade de conhecer e de agir em um determinado contexto social, ou seja, de desenvolver o conhecimento visando uma ação transformadora da sociedade. A essa consciência denominamos consciência informacional. ${ }^{5}$ Aliás, foi a partir dessa teoria que surgiu a motivação para a pesquisa desenvolvida no âmbito do grupo CRIDI que, por reconhecer a insuficiência ou ausência de políticas de salvaguarda digital, está empenhado, nessa fase da pesquisa, em disponibilizar para as instituições de países de língua latina um repositório digital arquivístico que está sendo desenvolvido pelo CRIDI, com recursos e apoio do CNPq e da Universidade Federal da Bahia, desde 2005.

Retomando as questões conceituais relativas ao termo informação, queremos então definir, já na partida, que não pensamos a informação exclusivamente como uma representação de símbolos registrados em suportes, mas como um processo de ampliação da consciência, com todos os seus significados capazes de orientar e instruir processos sociais, sejam estes quais forem. É a partir desta abordagem, dialética materialista, que conduzimos as investigações desenvolvidas em nosso grupo de pesquisa. Importante ressaltar que estes entendimentos e abordagens vêm sendo conduzidos há décadas pela Ciência da Informação (CI).

Assim, no caso em questão, consideramos que a informação, uma vez "desterritorializada" de seus suportes analógicos pelo uso das tecnologias digitais na área de arquivos, permite pensar nos símbolos e seus significados como conteúdos informacionais "libertados" de seus suportes analógicos, do tipo fita, filme ou película. Importante destacar que esse acontecimento tecnológico, que inaugura o que alguns autores (CASTELLS, 1999; MATELLART, 2002) chamam de "sociedade da informação", permitiu, na área de arquivos, ampliar o acesso simultâneo de conteúdos informacionais digitais a todos aqueles que busquem a fruição, estudo ou pesquisa, seja como prova ou informação.

Quanto ao volume de informação digital que vem sendo produzido atualmente, a previsão é que a cada cinco anos ela cresça dez vezes. Em 2010, o volume era de algo em torno de cinco exabytes ${ }^{6}$ de informação digital produzida, o que corresponderia

5 Não nos aprofundaremos, aqui, na estrutura conceitual que deu forma à teoria da informação proposta como tese de doutoramento, em 2002, apresentada à Escola de Comunicação da Universidade Federal do Rio de Janeiro (ECO-UFRJ), numa parceria com o Instituto Brasileiro de Informação em Ciência e Tecnologia, do Ministério d Ciência, Tecnologia e Inovação (IBICT-MCTI). Veja Silva, 2002.

${ }^{6} 1$ Exabyte $=10^{18}$ bytes Cf. http://techcrunch.com/2010/08/04/schmidt-data/ Acesso: 6 Maio 2012.

\begin{tabular}{l|l|l|l|l|l|l|} 
(c) Rev. Digit.Bibliotecon. Cienc. Inf. & Campinas, SP & v.14 & n.3 & p.515-540 & set/dez. 2016 & ISSN 1678-765X \\
\hline
\end{tabular} 
aproximadamente a quase cinquenta exabytes, em 2015, ou o equivalente a 500 mil bibliotecas do Congresso Americano, que é a maior do mundo.

Essa informação nascida digital ${ }^{7}$ trafega em redes cada vez mais velozes e efêmeras. Preservar essas estruturas, ao menos em parte, em termos de conteúdo e ambiência tecnológica, é ainda um dos maiores desafios que os profissionais que lidam com os arquivos precisam enfrentar. O contexto tecnológico, onde a informação trafega, é constantemente alterado por um mercado ávido pelo lançamento de novas gerações de equipamentos e softwares que acabam por se tornarem incompatíveis com aqueles que lhes antecederam. A informação digital, ao ser gerada, precisa obedecer a certas normas, requisitos e padrões para que sua preservação e acesso continuado sejam alcançados pelo máximo de tempo possível.

Ao se refletir sobre a atual produção audiovisual, no Brasil, observa-se que, quase em sua totalidade, ela vem sendo gerada já em ambientes digitais sem necessariamente atender aos requisitos mínimos necessários a sua preservação e, mais ainda, verifica-se uma ausência de políticas públicas voltadas à salvaguarda digital, a despeito de iniciativas empreendidas pelo IBICT, a CTDE e o Arquivo Nacional que visam a criação de repositórios digitais confiáveis, em conformidade com as normas e padrões vigentes, da mesma forma que Por essa razão, vemos como fundamentais a reflexão acadêmica e intelectual e as ações técnicas operacionais direcionadas às questões da salvaguarda e do acesso continuado a representantes nascidos digitais ou digitalizados a partir de itens documentais audiovisuais. Isso porque consideramos que difundir o patrimônio audiovisual custodiado por instituições públicas é um passo importante para se alcançar um novo paradigma de relações e de correlações entre as instituições de custódia de documentação audiovisual e seus usuários, produtores, diretores, pesquisadores, estudantes e público interessado, em geral.

O artigo foi estruturado da seguinte maneira: esta Introdução contextualiza o problema de pesquisa e as motivações que levaram o Grupo CRIDI a desenvolver suas ações de pesquisa que serão detalhadas nas seções seguintes, além de fazer uma breve explanação sobre o conceito de informação utilizado. Nas seções seguintes apresentamos o percurso de pesquisa do Grupo de Estudos sobre Cultura, Representação e Informação Digitais (CRIDI) ${ }^{8}$ para em seguida, traçarmos de forma breve, a abordagem metodológica (a episteme) e o embasamento teórico que orientam a pesquisa Por fim, compartilhamos os resultados já alcançados e as ações ora em execução.

7Importante distinguir os termos documento digital - refere-se a objetos nascidos digitais, ou born digital daqueles produzidos em outro suporte e que sofreram digitalização para acesso. Cf. Dicionário Brasileiro de Terminologia Arquivística. Disponível em: www.conarq.arquivonacional.gov.br/Media/publicacoes/dicionrio de terminologia_arquivstica.pdf. Acesso em: 9 Maio 2012.

8 Cf. <http://www.cridi.ufba.br>. Acesso em: 24 Set. 2016

\begin{tabular}{l|l|l|l|l|l|l} 
(c) Rev. Digit.Bibliotecon. Cienc. Inf. & Campinas, SP & v.14 & n.3 & p.515-540 & set/dez. 2016 & ISSN 1678-765X \\
\hline
\end{tabular} 


\section{ANTECEDENTES DA PESQUISA}

Em 2005, o CRIDI deu início ao projeto de pesquisa "A conversão digital de documentos especiais de acervos públicos e a consciência informacional: aspectos técnicos e teóricos no âmbito da Ciência da Informação". ${ }^{9}$ Esta fase inicial do projeto permitiu coletar dados sobre acervos públicos fotográficos, sonoros e audiovisuais em 109 instituições públicas na cidade do Salvador, sendo que entre essas instituições, somente 35 mantinham documentação audiovisual. ${ }^{10}$

No ano de 2007, próximos à conclusão da primeira fase da pesquisa, participamos, na cidade do Rio de Janeiro, como coorganizadores, mas também como estudantes do primeiro curso promovido pelo ICCROM - International Centre for the Study for Preservation and Restauration of Cultural Property sobre o tema da salvaguarda audiovisual: SOIMA Safeguarding Sound and Imagem Collections ${ }^{11}$. A partir desta experiência teve andamento uma série de ações no âmbito acadêmico da área da CI e da Arquivologia, na Universidade Federal da Bahia, cujo currículo não previa quaisquer componentes curriculares relativos ao patrimônio audiovisual.

Assim, em 2008, criamos o curso "Introdução à salvaguarda de arquivos de som e imagem em movimento", no âmbito da disciplina "Estruturas e Linguagens da Informação II", do Programa de Pós-Graduação em Ciência da Informação (PPGCI-UFBA). Um ano depois, foi a vez da disciplina optativa "Organização e Preservação de Acervos Audiovisuais e Sonoros", no âmbito da graduação em Arquivologia (ICI-UFBA). Já em 2012, o curso criado em 2008 torna-se disciplina optativa efetiva, sendo denominada "Arquivos de Som e Imagem em Movimento" e que passa a ter seus conteúdos didáticos oferecidos na plataforma Moodle, da própria UFBA. Os objetivos destas iniciativas são o de atender as demandas de pesquisa, ensino e extensão no âmbito da disciplina.

Considerando a necessidade de se difundir e fortalecer o máximo possível esta temática e trazê-la para reflexão nas áreas arquivísticas e da $\mathrm{CI}^{12}$, muitas têm sido as participações do CRIDI em eventos, cursos e treinamentos, nacionais e internacionais.

9 Cf. <http://www.cridi.ici.ufba.br/?page_id=25>. Acesso em: 24 Set. 2016

10 Naquela primeira fase do projeto tivemos apoio financeiro da UFBA, da Fundação de Amparo à Pesquisa do Estado da Bahia (FAPESB) e do Conselho Nacional de Desenvolvimento Científico e Tecnológico do Ministério da Ciência, Tecnologia e Inovação (CNPq-MCTI), através de nove Bolsas de Iniciação Científica, cada uma com 12 meses de duração, do Programa Institucional de Bolsas de Iniciação Científica (PIBIC), distribuídas ao longo dos três anos da pesquisa, para estudantes de graduação em Arquivologia.

11 Desta experiência resultou um artigo intitulado Toward a Curricular Structure. Cf. http://soima.iccrom.org/brazil-education/ . Acesso em: 24 Set. 2016.

12 Em 2013, apresentamos várias comunicações escritas em importantes eventos brasileiros da área arquivística e da ciência da informação e também de outras áreas afins, tais como: CINFORM - Encontro Nacional de Ensino e Pesquisa em Informação (SILVA, 2013a); ENECULT - Encontro de Estudos Multidisciplinares em Cultura (SILVA, 2013e); SBA - Simpósio Baiano de Arquivologia (SILVA, 2013b), o CTCM - Conferência sobre Tecnologia, Cultura e Memória (SILVA, 2013f); e publicamos artigos em dois periódicos científicos de destaque na área (SILVA, 2013c; 2013d). Em 2014, fizemos palestras no SINPRED - I Seminário Internacional

\begin{tabular}{l|l|l|l|l|l|l|} 
(c) Rev. Digit.Bibliotecon. Cienc. Inf. & Campinas, SP & v.14 & n.3 & p.515-540 & set/dez. 2016 & ISSN 1678-765X \\
\hline
\end{tabular}


Em 2013, demos início à segunda fase da pesquisa (2013-2016), agora exclusivamente limitada aos acervos audiovisuais, por meio do projeto "Desafios e alternativas digitais para a salvaguarda e difusão do patrimônio público documental arquivístico audiovisual". ${ }^{13}$ Em 2015, portanto, dez anos depois, os dados coletados, em Salvador, estão sendo atualizados, o que tem nos permitido perceber o estado da preservação do patrimônio audiovisual das instituições que responderam ao questionário para fazer análises comparativas que estão nos possibilitando conhecer a evolução, involução ou estagnação da preservação destas instituições. Dessa forma, pretende-se inferir e avaliar o nível de compromisso das esferas públicas decisórias acerca da salvaguarda do patrimônio audiovisual, na cidade do Salvador. Nesta segunda fase da pesquisa, outras instituições em Salvador, oito estados brasileiros e o Distrito Federal também aderiram ao projeto que já contava com a adesão inicial de 35 instituições. ${ }^{14}$ No total, coletamos dados de sessenta e cinco instituições/setores/organizações que possuem uma significativa representação na área do patrimônio audiovisual no país.

O questionário aplicado junto aos gestores dos acervos audiovisuais procurou identificar: 1) temas que caracterizam os acervos; 2) formatos e suportes existentes; 3) instrumentos utilizados para o controle de consultas ao acervo; 4) serviços e equipamentos oferecidos aos usuários; 5) indicações sobre prioridades para uma primeira ação de conversão digital; 6) o conhecimento técnico das equipes, relativas a tratamento de acervos originais (analógicos) e de digitalização de acervos de imagem em movimento; 7) equipamentos disponíveis nos setores de documentação audiovisual; 8) existência de normativas internas, políticas de preservação e planos de desastres para a salvaguarda das imagens da instituição; 9) experiências prévias de digitalização de acervos de imagem em movimento, bem como sobre a constituição das equipes e eventuais consultorias contratadas para esta finalidade;10) a origem dos recursos financeiros e materiais de tais experiências; 11) existência de relatórios técnicos de experiências eventualmente realizadas de conversão digital de imagem em movimento; 12) aspectos predominantes dos processos decisórios sobre o que digitalizar em

de Preservação Digital (SILVA, 2014a), e apresentamos o andamento de nossa pesquisa na Mesa Internacional de Abertura do $9^{\mathrm{a}}$ CineOP - Mostra de Cinema de Ouro Preto $/ 9^{\circ}$ Encontro de Arquivos Nacionais e Acervos Audiovisuais Brasileiros (SILVA, 2014b).

13 Nesta segunda fase da pesquisa já conseguimos apoio da UFBA, FAPESB e CNPq, para 13 Bolsas PIBIC, até o momento (maio de 2016), para estudantes de graduação em Arquivologia, Biblioteconomia, Direito, História e Humanidades; uma Bolsa CNPq -IC de três anos de duração, para uma estudante de graduação em Biblioteconomia; uma Bolsa CNPq de Apoio Técnico de Nível Superior (CNPQ-AT-NS), de três anos de duração, para um profissional de web design e de sistemas de internet; e uma Bolsa de Produtividade em Pesquisa (CNPq-PQ2), de três anos de duração, para a Coordenação do projeto. O projeto recebeu ainda um pequeno complemento de $\mathrm{R} \$ 7.500,00$ (sete mil e quinhentos reais) para despesas de custeio e capital, em Edital de Chamada Universal (CNPq). No total, nesta segunda fase do projeto, já alcançamos recursos da ordem de $\mathrm{R} \$ 187.000,00$ (cento e oitenta e sete mil reais).

14 Além da Bahia, coletamos dados em instituições de Brasília (Distrito Federal) e dos estados de Espírito Santo, Goiás, Minas Gerais, Paraná, Pernambuco, Rio de Janeiro, Rio Grande do Sul e São Paulo. Veja na aba <PROJETOS>, em <http://www.cridi.ici.ufba.br>, os links para os sites das instituições/setores/organizações colaboradoras do projeto.

\begin{tabular}{l|l|l|l|l|l|l|}
\hline (C) Rev. Digit.Bibliotecon. Cienc. Inf. & Campinas, SP & v.14 & n.3 & p.515-540 & set/dez. 2016 & ISSN 1678-765X \\
\hline
\end{tabular} 
cada instituição, bem como se as operações de digitalização foram realizadas internamente ou se foram contratadas externamente; 13) aspectos técnicos do processo de digitalização ${ }^{15}$.

O objetivo desta coleta de dados foi a de conhecer o quê, como e porquê vem sendo feito em termos de digitalização de acervos audiovisuais analógicos e identificar informação relevante para extrair dados destas experiências, e assim reunir elementos de aperfeiçoamento visando ações colaborativas que resultem na utilização de um ambiente online comum de preservação e acesso digitais aos acervos audiovisuais existentes. Todas estas instituições/ setores/organizações colaboradoras no desenvolvimento da pesquisa serão beneficiadas no futuro, não somente obtendo maior visibilidade por meio da divulgação de seus acervos no site do Grupo CRIDI, mas também recebendo previamente os dados, para assim estabelecer correlações e comparações, bem como novas relações interinstitucionais, e o mais importante: serem identificadas como parceiras de primeira hora do desenvolvimento do ambiente Legatum e que já estamos utilizando para experimentarmos ações de descrição, acesso e preservação arquivística dos arquivos digitais audiovisuais de seus acervos.

Ainda com referência a esta fase da pesquisa, inicialmente o projeto limitou a coleta de dados às instituições públicas, mas após nossa participação, em 2014, na $9^{a}$ CineOP Mostra de Cinema de Ouro Preto ${ }^{16}$, "fórum dedicado à preservação audiovisual em diálogo com a educação e em intercâmbio com o mundo" (D'ANGELO e D'ANGELO, 2014, p.3), decidimos abrir nosso escopo. Durante os Encontros Nacionais de Arquivos e Acervos Audiovisuais Brasileiros que acontecem no âmbito desta Mostra, e que reúnem as mais importantes instituições e organizações do país, foi que percebemos a importância de também incluir entidades privadas que demonstrassem interesse em colaborar com nosso projeto.

Três importantes organizações passaram, então, a colaborar com nosso projeto respondendo nosso questionário: a Cinemateca do Museu de Arte Moderna do Rio de Janeiro, o Centro de Documentação da Rede Globo de Televisão, do Estado do Rio Grande do Sul, e o Instituto Goiano de Pré-História e Antropologia, da Pontifícia Universidade Católica do Estado de Goiás.

15 Referem-se a nomes de arquivos, metadados, requisitos de qualidade, equipamentos utilizados, periodicidade de calibragens, versões e formatos gerados de um mesmo item convertido, armazenamento, guias de melhores práticas e padrões nacionais e internacionais adotados, normativas de salvaguarda eventualmente produzidas, políticas de acesso.

16 Cf. http://www.universoproducao.com.br/cineop/9cineop/ . Acesso em: 24 Set. 2016

\begin{tabular}{|c|c|c|c|c|c|l} 
(C) Rev. Digit.Bibliotecon. Cienc. Inf. & Campinas, SP & v.14 & n.3 & p.515-540 & set/dez. 2016 & ISSN 1678-765X \\
\hline
\end{tabular}




\section{FUNDAMENTOS METODOLÓGICOS:}

Nossa pesquisa relaciona-se à evolução/superação de um modelo analógico para um modelo digital. O pressuposto é que se trata de uma importante mudança paradigmática, representada pelo binômio analógico/digital que se apresenta como irreversível na sociedade e mesmo na relação do humano com a natureza.

A abordagem dialética materialista já mencionada favorece a observação e análise de movimentos de superação e de transformação. A dialética é uma postura, uma concepção de mundo, mas também um método de investigação e análise que permite uma apreensão da realidade. Esta abordagem, visando simultaneamente à totalidade e suas partes e apresentando-se ao mesmo tempo como análise e síntese, comporta sempre um abalo dirigido a todo conhecimento rígido: nas causas internas de seu desenvolvimento encontram-se as razões para a mudança (BRUYNE; HERMAN; SCHOUTHEETE, 1977).

Ao refletir e investigar sobre as questões envolvidas pela problemática da pesquisa e os processos de digitalização, entendemos que estes deverão ser analisados não como objetos fixos, mas como um processo dinâmico, em movimento e constante transformação: findo um processo, inicia-se outro. Os desafios e alternativas digitais para a salvaguarda e difusão do patrimônio público documental arquivístico audiovisual, objeto da investigação da Fase 2 de 3 da pesquisa, sem dúvida reúnem "uma nova forma que suprime e contém, ao mesmo tempo, as primitivas propriedades". Por isso, pergunta-se: Que mudanças advêm da digitalização dos documentos? Para respondê-la, deve-se ir além dos aspectos técnicos, ou seja, será "preciso indagar sobre o sentido histórico, social, político e técnico da pesquisa". ${ }^{17}$

Com relação à necessidade de se avançar na pesquisa de modo a estudar fatores que interferem nas decisões sobre o quê, porquê e como digitalizar, os resultados não devem ficar restritos a uma situação particular sob estudo e, portanto, devem ser generalizáveis. É preciso pois proporcionar um conhecimento novo a respeito de um fenômeno (uso das tecnologias digitais) ou de uma área (a preservação audiovisual) para relacioná-lo ao que já se sabe $a$ priori.

Para o desenvolvimento da pesquisa adotamos os procedimentos dos métodos historiográfico, estatístico, quantitativo, qualitativo, infográfico e, especialmente, comparativo, bem como da pesquisa de ação, em conjunto com técnicas específicas de coleta de dados. Na pesquisa de ação os próprios membros da organização que desejam mudanças organizacionais ou procedimentais devem participar da definição e do estabelecimento dos novos modelos que demandam, e que acabarão por impingir mudanças nos próprios procedimentos do grupo como um todo. 
Ao longo do processo de investigação sentimos a necessidade de conhecer os contextos de produção e de recepção dos acervos. Ou seja, procuramos compreender as situações atual e desejada das imagens em movimento e as demandas e necessidades de consulta e acesso a este tipo de acervo. Para tanto, vimos adotando em nossa coleta de dados, técnicas de documentação indireta para a pesquisa bibliográfica e a navegação na internet, e de documentação direta, através da observação intensiva (ver documentos, contatar membros de instituições, examinar fatos e fenômenos) e da observação extensiva (questionário impresso, formulários online, testes).

\section{EMBASAMENTO TEÓRICO}

Nosso ponto de vista não é a do sujeito como extensão do objeto, e sim a do sujeito como ação, ser social e histórico, já que é ele que "embora determinado por contextos econômicos, políticos e culturais, é o criador da realidade social e o transformador desses contextos" (GAMBOA, 1989, p. 103).

A categoria fundamental que queremos visualizar é a da totalidade e não a da lei. Nossa perspectiva teórico-metodológica assume a compreensão acerca do processo informacional pela ótica de uma teoria marxiana da consciência. Entendemos que o que importa é favorecer a expansão da consciência, utilizando, para tal, no processo informacional, a possibilidade de ampliação do acesso digital aos documentos arquivísticos audiovisuais.

O entendimento é elaborado em contraposição à compreensão segundo a qual a informação se define como um elemento, efeito, estrutura, conteúdo ou suporte físico com símbolos nele arranjados. Entender a informação como processo orientado à ampliação da consciência é uma forma de nos mantermos interrogando sobre as questões das relações sociais, das relações intersubjetivas, recolocando a questão do poder, da história e da cultura, como já sugeriu Chauí (1999). A informação está relacionada à nossa própria capacidade de existir no mundo e não a uma estrutura ou superestrutura determinada.

Menezes (1998) é um autor que indaga "qual a natureza do objeto material como documento, em que reside sua capacidade documental, como pode ele ser suporte da informação?", ou, dito de outra forma: que tipo de informação intrínseca os artefatos podem conter, especialmente os de conteúdo histórico? Esse autor desenvolve sua análise argumentando sobre a permanente transformação a que estão sujeitos também os objetos, seja na sua morfologia, na sua função, no seu sentido, seja isolada, alternada ou de forma cumulativa: "os objetos materiais têm uma trajetória, uma biografia (...) Não se trata de recompor um cenário material, mas de entender os artefatos na interação social (...) A biografia dos objetos introduz novo problema: a biografia das pessoas nos objetos" (MENEZES, 1998, p. 1-6). 
Reportando-se à "categoria sociológica do objeto histórico", cujos "compromissos são essencialmente com o presente, pois é no presente que eles são produzidos ou reproduzidos como categoria de objeto e é às necessidades do presente que eles respondem" e à "categoria cognitiva documento histórico", o autor oferece elementos relevantes para o desenvolvimento de nossa proposta de investigação, quanto ao pensamento dialético que a fundamenta e organiza, útil para avançar na reflexão acerca da relação documento histórico / informação, já que, ao considerar o problema, opta por reduzir a argumentação a sua mínima expressão.

O desafio está posto, de certa forma, ao trabalharmos na interface arquivística da ciência da informação: vamos procurar novas trilhas, procurando argumentar no desenvolvimento do projeto sobre a importância do acesso digital aos documentos audiovisuais públicos como instância de ampliação da consciência, de geração de novas vozes que fazem parte do processo histórico, dos estudantes, dos educadores, dos curiosos, deste mundo de subjetividade que a internet possibilita e forja. Que as interpretações mais precisas permaneçam com os especialistas, mas que se permita o caminhar subjetivo, o navegar pela subjetividade das redes, pois como já dizia Cervantes pela boca do engenhoso fidalgo de la Mancha: "El camino es siempre mejor que la posada".

\section{RESULTADOS PARCIAIS E AÇões EM EXECUÇÃo}

Nesta seção, apresentaremos os resultados parciais da pesquisa e as ações que estão em andamento. Importante destacar que coletamos dados de instituições e de usuários dos acervos. Entendemos que os gráficos aqui exibidos dispensam comentários explicativos sobre seus conteúdos, por considerar que são explícitos, claros, objetivos e que estender qualquer maior detalhe resultaria em redundância desnecessária.

\subsection{A infografia dos dados coletados}

A seguir apresentamos uma amostra dos dados coletados junto a instituições e usuários colaboradores da pesquisa.

\subsubsection{Dados das instituições}

Com relação aos dados institucionais que coletamos na Fase 2 (2013-2016), recentemente concluída, conforme já mencionado, reunimos dados de 62 instituições públicas e de três organizações da esfera privada, totalizando 65 respondentes entre 04.abr.2014 e 25.jun.2015, sendo que a análise dos dados propriamente dita teve início somente em meados de julho de 2015. Ressaltamos que não fizemos ainda a análise qualitativa dos dados das instituições, apenas os apresentamos graficamente, uma vez que tal análise iniciou-se agora, na última fase da pesquisa, a Fase 3 (2016-2019). 
A seguir, apresentamos um quadro com o nome das 65 instituições colaboradoras que responderam ao nosso questionário.

Quadro 1. Instituições que responderam o instrumento de coleta de dados

\begin{tabular}{|c|c|}
\hline $\mathbf{N}^{\mathbf{0}}$ & 65 Instituições respondentes \\
\hline 01 & $\begin{array}{l}\text { Acervo do Museu da Imagem e do Som de Belo Horizonte (antigo Acervo do Centro de Referência } \\
\text { Audiovisual de Belo Horizonte) }\end{array}$ \\
\hline 02 & Centro de Documentação da Fundação Padre Anchieta \\
\hline 03 & Núcleo de Memória das Artes da Fundação Cultural do Estado da Bahia \\
\hline 04 & Diretoria de Conservação de Documentos do Arquivo Público Mineiro \\
\hline 05 & Subgerência de Documentação Especial do Arquivo Geral da Cidade do Rio de Janeiro \\
\hline 06 & VídeoSaúde Distribuidora da Fundação Oswaldo Cruz do Rio de Janeiro \\
\hline 07 & Setor de Preservação da Cinemateca Brasileira \\
\hline 08 & Arquivo Público Municipal de Bagé - Tarcísio Taborda \\
\hline 09 & Setor de Arquivos Audiovisuais da Fundação Gregório de Mattos \\
\hline 10 & Arquivo Histórico Regional da Universidade de Passo Fundo \\
\hline 11 & Fototeca do Arquivo Histórico Municipal João Spadari Adami (Caxias do Sul) \\
\hline 12 & Biblioteca da Faculdade de Arquitetura da Universidade Federal da Bahia \\
\hline 13 & Secretaria da TV do Senado Federal \\
\hline 14 & $\begin{array}{l}\text { Supervisão de Documentação e Disseminação de Informações da Unidade Estadual da Bahia do } \\
\text { Instituto Brasileiro de Geografia e Estatística }\end{array}$ \\
\hline 15 & Seção Memória da Biblioteca Universitária Reitor Macedo Costa da Universidade Federal da Bahia \\
\hline 16 & Memorial Lindembergue Cardoso da Escola de Música da Universidade Federal da Bahia \\
\hline 17 & $\begin{array}{l}\text { Acervo Audiovisual e Documental do Instituto Goiano de Pré-História e Antropologia da Pontifícia } \\
\text { Universidade Católica de Goiás }\end{array}$ \\
\hline 18 & Cinemateca de Curitiba da Fundação Cultural de Curitiba \\
\hline 19 & $\begin{array}{l}\text { Seção Técnica de Audiovisual da Faculdade de Arquitetura e Urbanismo da Universidade de São } \\
\text { Paulo }\end{array}$ \\
\hline 20 & Centro de Documentação da TV da Universidade Federal de Minas Gerais \\
\hline 21 & Setor de Audiovisual da Fundação Museu da Imagem e do Som do Rio de Janeiro \\
\hline 22 & Laboratório Memória e Cinema da Escola de Belas Artes da Universidade Federal da Minas Gerais \\
\hline 23 & TV da Universidade Federal da Bahia \\
\hline 24 & Centro de Documentação e Memória da Cinemateca Capitólio \\
\hline 25 & Seção de Biblioteca, Informação e Memória do Tribunal Regional Eleitoral da Bahia \\
\hline 26 & Memorial da Faculdade de Direito da Universidade Federal da Bahia \\
\hline 27 & Biblioteca Djalma Ramos da Maternidade Climério de Oliveira da Universidade Federal da Bahia \\
\hline 28 & Centro de Memória da Bahia da Fundação Pedro Calmon (não há setor específico) \\
\hline 29 & Biblioteca do Instituto de Ciência da Informação da Universidade Federal da Bahia \\
\hline 30 & Centro de Documentação da Fundação TV Minas Cultural e Educativa \\
\hline 31 & Biblioteca da Faculdade de Economia da Universidade Federal da Bahia \\
\hline 32 & Biblioteca Setorial - Escola de Medicina Veterinária e Zootecnia da Universidade Federal da Bahia \\
\hline 33 & Núcleo de Acervo Iconográfico e Cartográfico do Arquivo Público do Estado de São Paulo \\
\hline 34 & Núcleo de Memória da Diretoria do Audiovisual da Fundação Cultural do Estado da Bahia \\
\hline 35 & $\begin{array}{l}\text { Setor de Acervo Audiovisual do Centro Técnico Audiovisual da Secretaria do Audiovisual do } \\
\text { Ministério da Cultura }\end{array}$ \\
\hline 36 & Arquivo de Filmes da Cinemateca do Museu de Arte Moderna do Rio de Janeiro \\
\hline 37 & Coordenação de Processamento e Preservação do Acervo do Arquivo Nacional \\
\hline 38 & Divisão de Arquivos Permanentes do Arquivo Público da Cidade de Belo Horizonte \\
\hline 39 & Setor de Audiovisual do Museu da Imagem e do Som de Campinas \\
\hline 40 & Gerência Executiva de Acervo da Empresa Brasil de Comunicação \\
\hline 41 & Biblioteca Setorial - Instituto de Química da Universidade Federal da Bahia \\
\hline 42 & Setor de Braille da Biblioteca Pública do Estado da Bahia \\
\hline 43 & Supervisão de Acervo Permanente do Arquivo Histórico de São Paulo \\
\hline 44 & Acervo de Documentação Histórica Musical da Universidade Federal da Bahia \\
\hline 45 & \\
\hline
\end{tabular}

\begin{tabular}{l|l|l|l|l|l|l|}
\hline (O) Rev. Digit.Bibliotecon. Cienc. Inf. & Campinas, SP & v.14 & n.3 & p.515-540 & set/dez. 2016 & ISSN 1678-765X \\
\hline
\end{tabular} 
46 Biblioteca da Faculdade de Filosofia e Ciências Humanas da Universidade Federal da Bahia

47 Biblioteca do Instituto de Física da Universidade Federal da Bahia

48 Coordenação de Documentação Multimídia da Agência de Notícias do Senado Federal

49 Coordenação de Arquivo da Câmara dos Deputados

50 Centro de Estudos Baianos da Biblioteca Universitária Reitor Macedo Costa da Universidade Federal

da Bahia

51 Núcleo de TV Universitária da Universidade Federal da Santa Maria

52 Cinemateca Ludovico Persice do Arquivo Público do Estado do Espírito Santo

53 Videoteca da Escola de Formação Complementar do Exército e Colégio Militar de Salvador

54 Setor de Multimeios da Biblioteca Teixeira de Freitas da Faculdade de Direito da Universidade

54 Federal da Bahia

55 Biblioteca da Escola de Administração da Universidade Federal da Bahia

56 Memorial Denis Bernardes da Universidade Federal de Pernambuco

57 Núcleo de Audiovisual da Assessoria de Comunicação da Universidade Federal do Recôncavo da

57 Bahia

58 Centro de Documentação do Conselho Regional de Medicina da Bahia

59 Multiteca da Faculdade de Comunicação da Universidade Federal da Bahia

60 Faculdade de Educação da Universidade Federal da Bahia (setor não identificado)

61 Biblioteca da Faculdade de Educação da Universidade Federal da Bahia

62 Centro de Memória e Informação do Museu da Imagem e do Som de São Paulo

63 Biblioteca Nelson Araújo da Escola de Teatro da Universidade Federal da Bahia

64 Secretaria Administrativa da Escola Politécnica da Universidade Federal da Bahia (não há setor específico)

65 Centro de Documentação da RBSTV-RS - Rede Globo

Fonte: Os Autores da pesquisa

Na sequência, apresentamos alguns gráficos que representam uma amostragem dos dados coletados ${ }^{18}$ junto às 65 instituições colaboradoras elencadas no Quadro 1.

A Figura 1 apresenta os formatos/suportes existentes nos acervos pesquisados. Chama a atenção o fato de que em todos os diferentes tipos de suportes/formatos apontados algumas instituições indicam que não sabem se tal suporte ou formato existe em seu acervo, ou ainda, que não sabem identificar o suporte ou formato, para poderem indicar se existem ou não.

$18 \mathrm{O}$ conjunto consolidado e integrado dos dados de todas as instituições podem ser acessados em <http://www.cridi.ici.ufba.br/respostas-2014-2015/Resumo-dados-institucionais-2014-2015.pdf〉. Também podem ser consultados por instituição específica, em 〈http://www.cridi.ici.ufba.br/?page_id=1071 >.

\begin{tabular}{l|l|l|l|l|l|l} 
(c) Rev. Digit.Bibliotecon. Cienc. Inf. & Campinas, SP & v.14 & n.3 & p.515-540 & set/dez. 2016 & ISSN 1678-765X \\
\hline
\end{tabular}




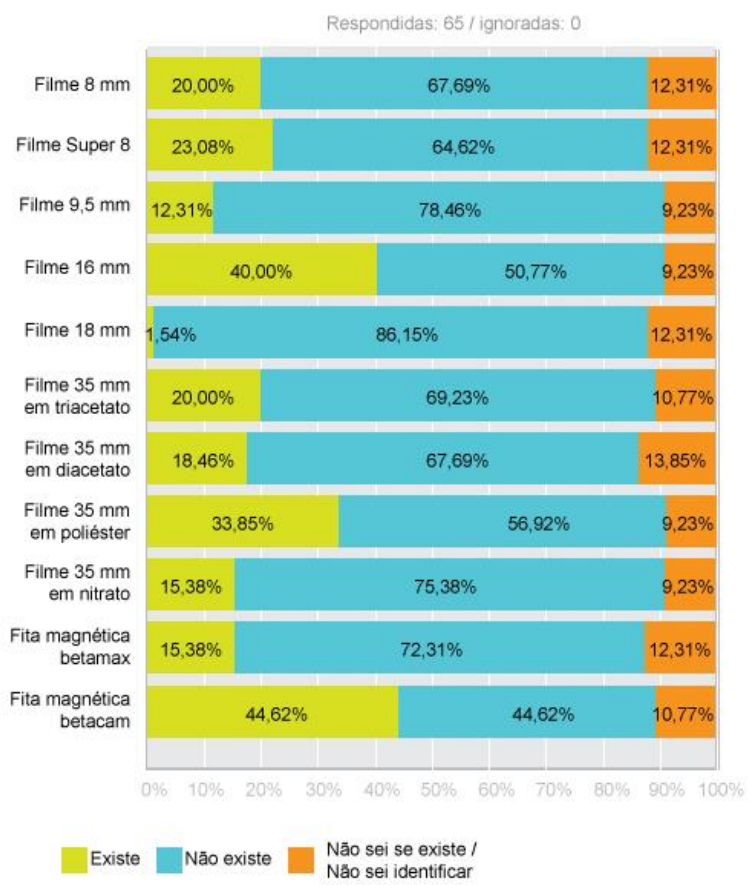

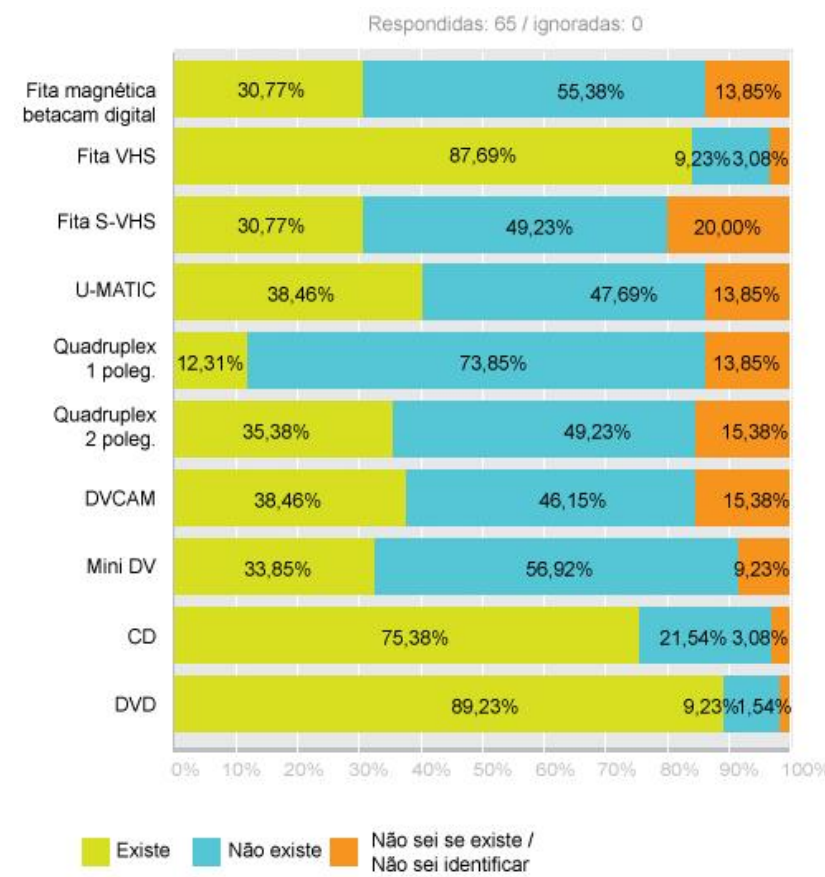

Figura 1. Formatos/suportes existentes nos acervos de imagens em movimento pesquisados Fonte: Os Autores da pesquisa

A Figura 2 demonstra que as instituições não têm investido adequadamente em treinamento para seus funcionários.

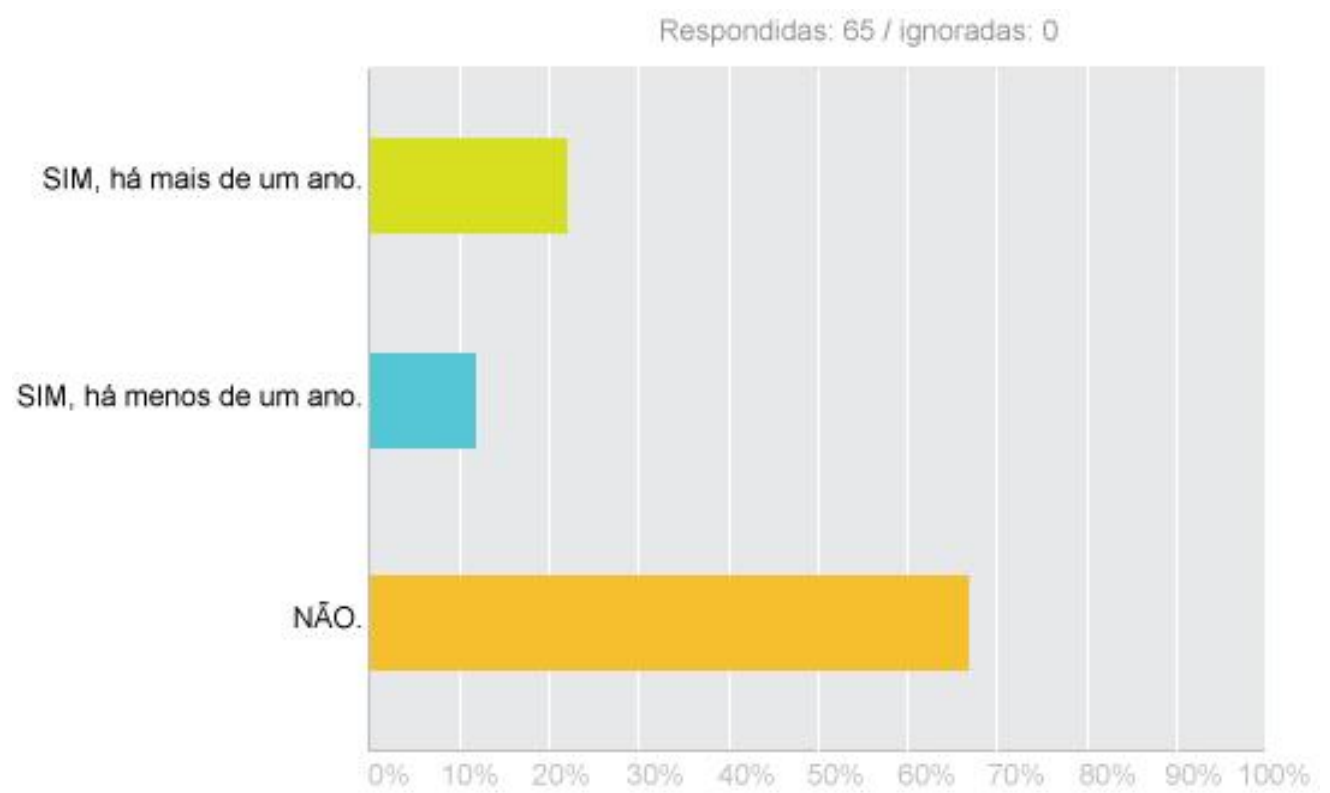

Figura 2. Algum funcionário do setor já participou de curso sobre tratamento de acervos de imagens em movimento?

Fonte: Os Autores da pesquisa 
Na Figura 3 constata-se que pouco mais de 10\% das instituições pesquisadas não sabem informar se existe um plano de desastres para seus acervos analógicos audiovisuais, e um grave cenário fica explícito: $70 \%$ das instituições não dispõem de um plano de desastres.

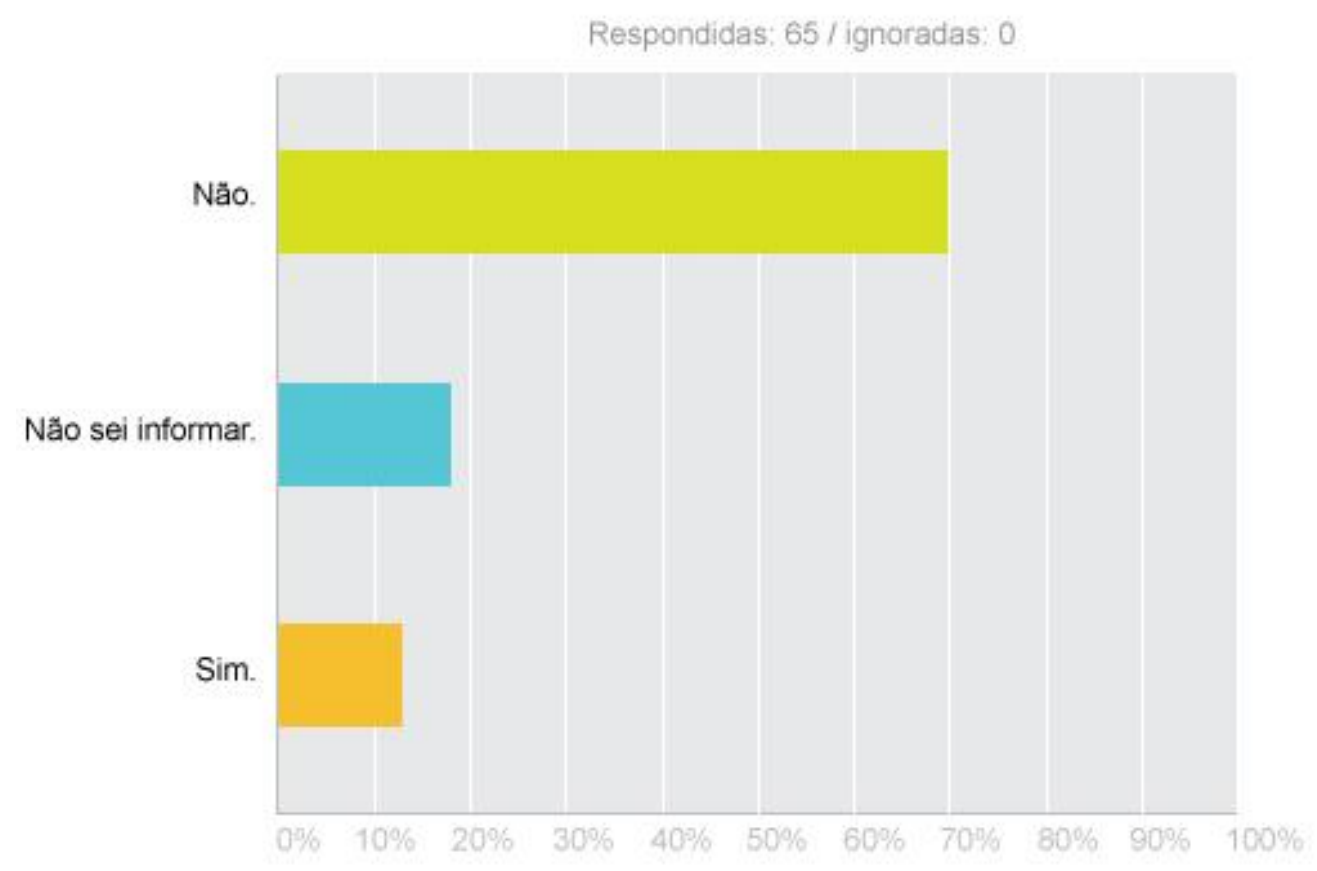

Figura 3. A instituição dispõe de um plano de desastres para a documentação audiovisual analógica? Fonte: Os Autores da pesquisa

$\mathrm{Na}$ Figura 4, que nos reporta apenas às instituições que desenvolveram algum projeto de digitalização de seus acervos, num total de 29 instituições ou setores de instituições (das 65 que responderam nosso questionário), outro aspecto de extremo descuido institucional se refere à forma como são armazenadas as versões máster de seus arquivos audiovisuais digitais: quase $50 \%$ das instituições os armazenam exclusivamente nos discos rígidos de seus computadores, pouco mais de $20 \%$ delas os mantêm em DVD, além dos quase $15 \%$ que nem sabem aonde ficam armazenadas tais versões máster. Um completo absurdo. Apenas aproximadamente $20 \%$ das instituições que produzem versões máster de seus arquivos audiovisuais agem de forma cuidadosa e regulamentar, adotando a fita LTO (linear tape open) como suporte para suas versões máster de documentos audiovisuais. 


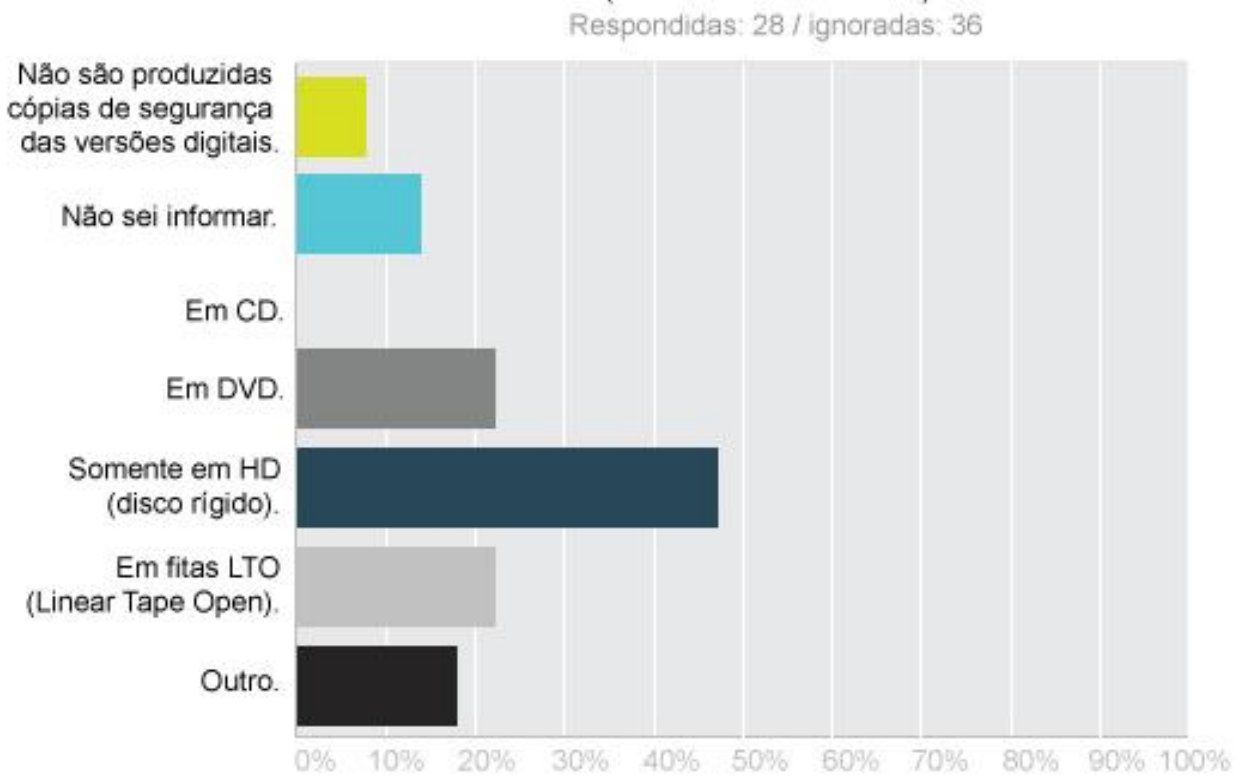

Figura 4. Como é armazenada a cópia de segurança da versão de maior resolução de cada item (versão matriz ou master)?

Fonte: Os Autores da pesquisa

\subsubsection{Dados dos usuários}

Com relação aos usuários, reunimos dados de 15 (quinze) indivíduos, no período entre 15.abr.2014 e 12.mar.2015, sendo que só foi possível dar início à análise dos dados em meados de julho de 2015. A ressalva é que aqui não analisaremos os dados dos usuários, apenas os apresentamos graficamente. Esta atividade analítica continuará na última fase da pesquisa, a Fase 3 (2016-2019). Responderam nosso questionário os usuários das seguintes instituições:

Quadro 2. Instituições nas quais houve usuários que colaboraram com a pesquisa (responderam o instrumento de coleta de dados)

\begin{tabular}{|c|c|}
\hline $\mathbf{N}^{\mathbf{0}}$ & Instituições nas quais houve respostas de indivíduos consulentes do acervo audiovisual \\
\hline 01 & UFBA - Biblioteca Anísio Teixeira / Faculdade de Educação \\
\hline 02 & UFBA - Biblioteca Djalma Ramos / Maternidade Climério de Oliveira \\
\hline 03 & Fundação TV Minas Cultural e Educativa \\
\hline 04 & UFBA - Escola Politécnica \\
\hline 05 & Biblioteca Teixeira de Freitas \\
\hline 06 & Arquivo Nacional \\
\hline 07 & $\begin{array}{l}\text { Museu da Imagem e do Som de Belo Horizonte (antigo Centro de Referência Audiovisual de Belo } \\
\text { Horizonte) }\end{array}$ \\
\hline 08 & Cinemateca Brasileira \\
\hline 09 & Cinemateca Brasileira \\
\hline 10 & Arquivo Público Mineiro \\
\hline 11 & Arquivo Público da Cidade de Belo Horizonte \\
\hline 12 & Prefeitura Municipal de Engenheiro Navarro \\
\hline 13 & Arquivo Público Mineiro \\
\hline 14 & Secretaria de Estado de Cultura de Minas Gerais \\
\hline
\end{tabular}

\begin{tabular}{l|l|l|l|l|l|l}
\hline (C) Rev. Digit.Bibliotecon. Cienc. Inf. & Campinas, SP & v.14 & n.3 & p.515-540 & set/dez. 2016 & ISSN 1678-765X \\
\hline
\end{tabular}


15

Museu da Imagem e do Som de Belo Horizonte (antigo Centro de Referência Audiovisual de Belo Horizonte)

Fonte: Os Autores da pesquisa

Os 15 respondentes se enquadram nas seguintes categorias profissionais: quatro bibliotecários, um produtor multimídia, um produtor/pesquisador de audiovisual, um cineasta, um gestor de audiovisual, um conservador audiovisual, três historiadores, sendo um deles também arquivista, um comunicólogo, um colaborador que se identificou como funcionário público municipal e outro como funcionário público estadual. A média da faixa etária entre eles é de 40 anos (entre 25 e 56 anos de idade), sendo $60 \%$ de indivíduos do gênero feminino.

Todos possuem computador e acesso à internet por conexão de banda larga em suas residências, sendo que apenas um usuário ainda utiliza conexão discada. Uma informação interessante diz respeito ao fato que antes deles se dirigirem às instituições para consultas aos acervos de imagem em movimento, $60 \%$ dos respondentes verificam previamente se a instituição disponibiliza estas imagens em seus sites na internet.

Os temas mais pesquisados são os seguintes:

- $\quad$ História da cidade $(73,33 \%)$;

- Inaugurações, reformas, serviços e obras públicas (60\%);

- $\quad$ Memória e museus (53,33\%);

- Congressos, cursos, debates, conferências, encontros, fóruns, mesas-redondas, palestras, seminário, simpósios $(53,33 \%)$;

- $\quad$ Biografias $(53,33 \%)$;

- $\quad$ Teatro $(46,67 \%)$

- $\quad$ Entrevistas, depoimentos (46,67\%);

- Cerimônias, despachos, discursos, homenagens, visitas, convênios, campanhas e solenidades oficiais $(46,67 \%)$;

- $\quad$ Carnaval $(46,67 \%)$;

- $\quad$ Natureza (40\%);

- $\quad$ Eventos culturais (40\%);

- Concertos, musicais, óperas, shows e recitais (40\%).

Os temas menos pesquisados são os seguintes:

- $\quad \operatorname{Circo}(6,67 \%)$;

- $\quad$ Aventura (13,33\%);

- $\quad$ Lançamentos de livros (13,33\%);

- Dança/Balé (13,33\%);

- $\quad$ Desenho animado (13,33\%);

- $\quad$ Ficção científica $(13,33 \%)$;

- Infantil (13,33\%);

- $\quad$ Eventos científicos (20\%); 
- $\quad$ Guerra (20\%);

- Manifestações étnicas/religiosas (20\%).

Dois usuários indicaram respostas específicas no campo "Outros", sendo elas:

- $\quad$ Memória do cinema e da televisão $(6,67 \%)$;

- $\quad$ Documentários em geral sobre Minas Gerais (6,67\%).

Quanto aos temas "Penitenciárias" e "Terror" não houve indicação de consulta pelos usuários. Os objetivos mais frequentes assinalados nas consultas foram os seguintes:

- $\quad$ Pesquisa para mestrado $(26,67 \%)$;

- $\quad$ Entretenimento/curiosidade (20\%) e

- $\quad$ Produção de filme $(13,33 \%)$.

Também foram indicados os seguintes objetivos: pesquisas de graduação, especialização, doutorado e produção de livro, cada um com 6,67\% de frequência. Dois respondentes indicaram no campo "Outros" os seguintes objetivos: "Pesquisa para novas obras audiovisuais para TV, cinema e exposição" $(6,67 \%)$ e por ser "Necessário às minhas atividades profissionais, especialmente preservação" $(6,67 \%)$.

Quando indagados se solicitariam cópia de algum documento do acervo de imagens em movimento, os usuários responderam conforme segue:

Tabela 1. Opções de usuários no caso de virem a solicitar cópia de algum documento do acervo de imagens em movimento

\begin{tabular}{|c|c|c|c|}
\hline \multicolumn{2}{|c|}{ Opções de resposta } & \multicolumn{2}{|c|}{ Respostas } \\
\hline \multicolumn{2}{|c|}{ Não } & $40,00 \%$ & 6 \\
\hline \multicolumn{2}{|c|}{ Sim, em CD, se possivel } & $13,33 \%$ & 2 \\
\hline \multicolumn{2}{|c|}{ Sim, em DVD, se possível } & $26,67 \%$ & 4 \\
\hline \multicolumn{2}{|c|}{ Sim, em VHS (fita magnética de vídeo), se possivel } & $0,00 \%$ & 0 \\
\hline \multicolumn{2}{|c|}{ Sim, enviando-me por email, se possivel } & $20,00 \%$ & 3 \\
\hline \multicolumn{2}{|c|}{ Sim, em pendrive } & $20,00 \%$ & 3 \\
\hline \multicolumn{2}{|c|}{ Outro (especifique) } & $13,33 \%$ & 2 \\
\hline \multicolumn{4}{|c|}{ Total de respondentes: 15} \\
\hline$n^{0}$ & Outro (especifique) & \multicolumn{2}{|l|}{ Data } \\
\hline 1 & seria bom se houvesse codecs para download & \multicolumn{2}{|c|}{$31 / 08 / 201416: 04$} \\
\hline 2 & HD & \multicolumn{2}{|c|}{$22 / 07 / 2014$ 11:10 } \\
\hline
\end{tabular}


Com relação aos formatos de arquivos digitais mais solicitados pelos usuários, obtivemos as seguintes respostas:

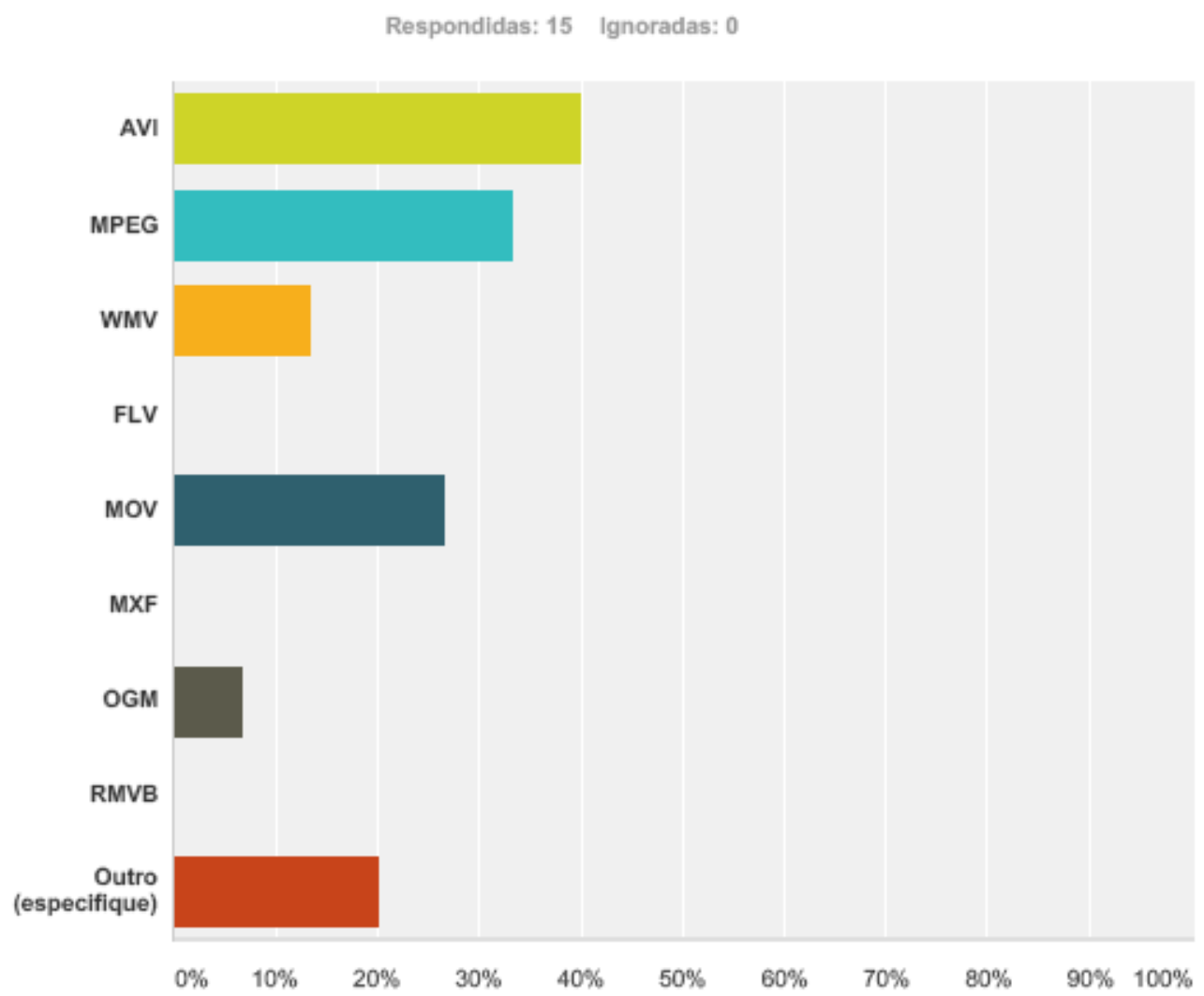

Figura 5. Em que formato de arquivo você solicitaria a versão digital do documento audiovisual?

Fonte: Os Autores da pesquisa

Em "Outros", na Figura 5, três usuários responderam, cada um: "JPG"; "Não sei” e "Normalmente usamos o que o arquivo fornece, nunca solicitei um codec específico".

As figuras apresentadas acima, relativas a usuários das instituições, representam a quase totalidade $^{19}$ dos dados coletados junto aos 15 usuários colaboradores.

\subsection{A iniciativa Legatum}

Antes do final do século passado, a preservação significava reter, guardar. Atualmente ela passa a se constituir como uma área associada ao acesso, formando um binômio em que preservar significa compartilhar, difundir. No universo digital, preservação e salvaguarda passam a ser sinônimos de acesso continuado, pelo maior tempo possível. Assim, prover meios de acesso ao legado registrado nos documentos de valor permanente e identificados

19 O conjunto consolidado e integrado desses dados pode ser acessados em <http://www.cridi.ici.ufba.br/respostas-2014-2015/Resumo-dados-individuais-2014-2015.pdf $>$.

\begin{tabular}{l|l|l|l|l|l|l|} 
(C) Rev. Digit.Bibliotecon. Cienc. Inf. & Campinas, SP & v.14 & n.3 & p.515-540 & set/dez. 2016 & ISSN 1678-765X \\
\hline
\end{tabular}


como pertencentes à sociedade nos quais foram produzidos é um fator determinante do momento atual, que extrapola o paradigma da restrição ao manuseio do original quando a preservação era o grande objetivo.

No Brasil, a partir do uso da internet nos anos 1990, as instituições arquivísticas pública $^{20}$ passaram a adotar requisitos e padrões formulados pela Câmara Técnica de Documentos Eletrônicos do Conselho Nacional de Arquivos e em normas internacionais visando ao tratamento arquivístico e à digitalização de documentos sob sua custódia e a empreender diversas ações que permitissem facilitar o acesso digital a seus acervos e que incluem os acervos audiovisuais e iconográficos em suas mais diversas formas. Diversos conteúdos relativos a esses acervos estão disponíveis na internet, outros, dadas as dificuldades de infraestrutura e pessoal enfrentadas pelas instituições arquivísticas, aguardam oportunidade para que possam ser digitalizados e tornados disponíveis em plataformas de acesso.

Considerando os esforços de preservação e acesso em um plano global, qualquer iniciativa de cooperação, integração e alcance internacional encontrará dificuldades a serem superadas entre os países participantes. Experimentar soluções colaborativas pode permitir não apenas o aprendizado científico durante o processo, mas a obtenção de um ou mais produtos úteis a um grupo de países de características essencialmente próximas (como a origem latina de seus idiomas oficiais), mas, ao mesmo tempo, diferenciados pelos contextos econômicos, culturais e sociais.

As proximidades linguísticas dos países de origem latina e que estão aptos a participar do repositório Legatum podem se manifestar de diferentes maneiras, algumas mais evidentes do que outras, como as proximidades culturais que foram carregadas pela herança linguística comum. Entendemos, como premissa, que o acesso, compreensão e identificação cultural entre diferentes povos podem ocorrer apesar das fronteiras culturais e barreiras linguísticas. Essa é a premissa que se quer adotar com o desenvolvimento do repositório digital Legatum.

Esta iniciativa Legatum surge no âmbito do projeto do Grupo CRIDI, a partir da ação de seus componentes. Sua primeira e possivelmente principal ação é gerar um produto de pesquisa que ofereça armazenamento e preservação continuadamente vigiada, qual seja, o repositório arquivístico Legatum.

O objetivo deste repositório é reunir dados de acervos audiovisuais custodiados por instituições de países de cultura latina cujas instituições arquivísticas públicas são custodiadoras destes acervos e fundos e coleções nos quais esses acervos estão vinculados.

20 Aquelas que realizam a gestão dos acervos produzidos por outras instituições públicas de uma mesma esfera de poder, em função das atividades de uma administração governamental, possuindo o arquivo como atividadefim. Além disso, esse tipo de instituição normalmente estabelece serviços para gestão e disponibilização dos acervos documentais sob sua guarda para a pesquisa histórico-cultural e apoio administrativo. Cf. Mariz, 2012. \begin{tabular}{l|l|l|l|l|l|l} 
(c) Rev. Digit.Bibliotecon. Cienc. Inf. & Campinas, SP & v.14 & n.3 & p.515-540 & set/dez. 2016 & ISSN 1678-765X \\
\hline
\end{tabular} 
Para a pesquisa, considerou-se apenas os países da chamada terceira geração, que podem ser facilmente identificados como aqueles que possuem como idioma oficial: Português, Espanhol, Catalão, Galego, Francês, Italiano e Romeno. Os idiomas Occitano ou Provençal, falado ao sul do rio Loire, na França e o Romanche, falado por aproximadamente 35.000 pessoas no cantão de Grisões, na Suíça, não foram incluídos nessa fase da pesquisa, tanto pela dificuldade em conseguir uma tradução completa da interface quanto da limitada quantidade de falantes atualmente, no entanto, há planos de inclusão dessas no futuro.

Como plataforma de acesso digital, o repositório Legatum possui uma instalação da segunda versão do software livre AtoM (anteriormente ICA-AtoM), com os idiomas supracitados ativos (sendo a tradução para o idioma romeno criado por meio de esforços do próprio grupo de pesquisa), além do inglês.

O trabalho ora sendo empreendido conta com a colaboração de outras instituições, grupos, pessoas e iniciativas com as quais o Grupo CRIDI vem estabelecendo relações. Da parte do próprio grupo, esforços estão sendo empreendidos na Fase 3 (2016-2019) para migrar dados de instituições e acervos já disponíveis na internet para o repositório ou solicitar tais dados diretamente das instituições. Uma vez que o trabalho possui potencial abrangente e de grande espectro, espera-se que a ação colaborativa seja uma aliada para que os objetivos sejam alcançados.

Atualmente, os membros do grupo de pesquisa, principalmente os bolsistasestudantes estão participando de um treinamento para inserção dos dados supracitados e para assim fazerem a crítica quanto às funcionalidades do Legatum.

O Legatum ${ }^{21}$ é um modelo de repositório aberto destinado ao acesso digital de informações relativas aos acervos audiovisuais públicos e, em direção ao futuro, com potencial para se transformar em um repositório arquivístico confiável para armazenamento de matrizes digitais audiovisuais. Trata-se de uma série de ações coordenadas ao redor de um repositório aberto, multi-idiomas e colaborativo. O repositório é baseado em uma plataforma de acesso digital em conformidade com normas arquivísticas, de forma a se tornar tão adequado quanto possível para alcançar os objetivos a que se propõe. As atividades já realizadas se referem a testes e discussões sobre a descrição arquivística multinível e de interrelacionamento entre tabelas do software, alterações na interface para melhor visualização dos conteúdos e formação de identidade visual, levando-se em conta a experiência e o perfil profissional de alguns dos integrantes do Grupo CRIDI e dos estudos na literatura existente, incluindo as normativas e adaptação da tradução oficial para português, considerando a variedade brasileira deste idioma, uma vez que há muitos termos provenientes da terminologia da variante europeia do português..

21 Cf. 〈http://www.cridi.ici.ufba.br/?page_id=489> e <http://www.legatum-si.net $>$.

\begin{tabular}{l|l|l|l|l|l|l|} 
(C) Rev. Digit.Bibliotecon. Cienc. Inf. & Campinas, SP & v.14 & n.3 & p.515-540 & set/dez. 2016 & ISSN 1678-765X \\
\hline
\end{tabular}


O resultado esperado ao final da Fase 3 (2016-2019) diz respeito a um ambiente para acesso e preservação arquivísticas digitais, bem como reunião e compartilhamento de descrições de acervos audiovisuais e iconográficos da cultura latina. Essa plataforma deverá permitir a percepção das semelhanças e diferenças entre as manifestações, diversidades e semelhanças culturais das tradições e práticas arquivísticas, além do incremento ao intercâmbio entre povos muitas vezes geograficamente distantes, mas próximos de uma herança cultural de raízes comuns. O exercício contínuo de idealização de novas formas de disponibilização digital de documentos audiovisuais será favorecido pela acumulação de conhecimento que a iniciativa deverá promover, documentar e divulgar.

Nosso compromisso está na busca constante de aprimoramento, a fim de tornar o processo cada vez mais direcionado às necessidades de informação dos usuários, e de contribuir para que o uso das tecnologias digitais favoreça o bom desempenho da instituição pública junto à sociedade. Acredita-se que desta maneira as instituições que custodiam tais acervos audiovisuais sejam reconhecidas como agentes que possibilitam a experiência e o reconhecimento da memória social e da história como meio de ampliação de consciência do indivíduo como parte da sociedade em que vivemos.

Abaixo, a imagem da primeira tela do repositório Legatum apresenta-se em inglês, idioma que é mantido como porta inicial na interface com o usuário, por ser a língua franca atual (o "Latim" contemporâneo).

\section{LEGATVM}

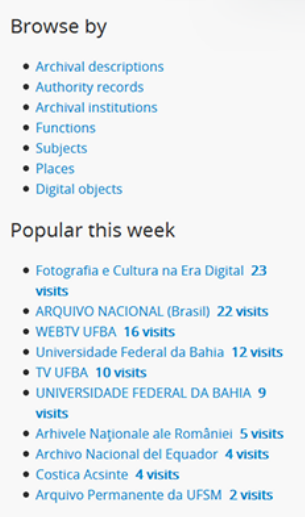

Welcome to Legatum

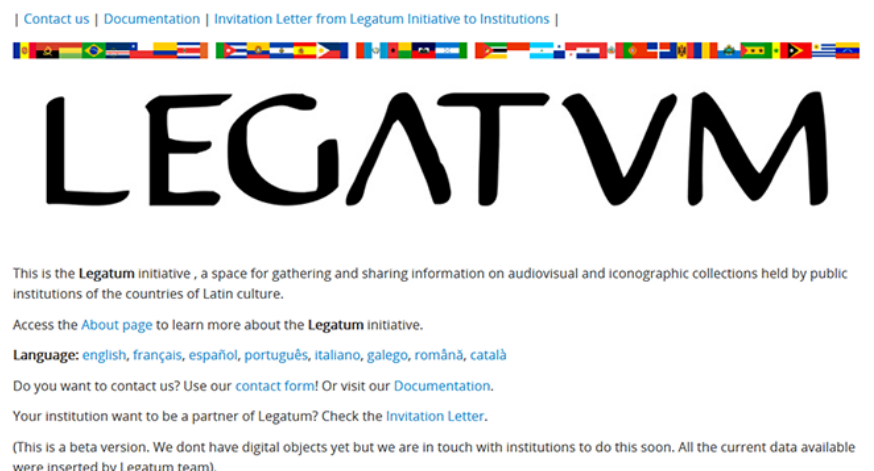

were inserted by Legatum tearn.

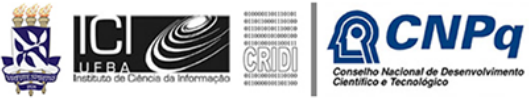

FIGURA 6. Tela principal do ambiente/plataforma da Iniciativa Legatum

Fonte: Os Autores da pesquisa 
Em um primeiro momento, conforme já mencionado, o repositório Legatum deverá reunir e divulgar representantes digitais de acervos arquivísticos audiovisuais produzidos ou custodiados no âmbito público dos países que possuem como idiomas oficiais os de origem latina já citados. O objetivo é identificar e descrever ou obter a descrição arquivística dos acervos audiovisuais custodiados por instituições que armazenem acervos com essa origem. A reunião desses elementos permitirá uma visão diferenciada dos dados disponíveis no Legatum favorecendo novos estudos e pesquisas na área.

A Iniciativa Legatum é uma experiência técnica que se utiliza dos avanços recentes da tecnologia da informação aplicada aos acervos permanentes e de fundamentos e desenvolvimentos da preservação digital. Mas também é uma iniciativa de reflexão sobre a informação, a cultura e a representação digitais, ou seja, um passo de convergência empírica que, ao mesmo tempo, oferece um produto de utilidade ao pesquisador interessado em acessar informações sobre os acervos audiovisuais.

O motivo inicial para a decisão de limitarmos a experiência do Legatum a sete idiomas de origem latina foi o de deixar um escopo internacional abrangente, mas ainda assim gerenciável. Pensamos inicialmente no espaço lusófono, mas depois consideramos que não haveria problemas em ampliar para os idiomas de raiz latina. Nos parece interessante a existência de um ambiente que demonstre que há algo em comum entre os países de língua de origem latina, mesmo estando em continentes diferentes, e mesmo que a herança latina se manifeste, algumas vezes, apenas linguisticamente, como pareceu ser o caso da Romênia quando iniciamos o projeto, mas cuja realidade de proximidade se mostrou animador no âmbito da cultura, o que evidencia a percepção de que um idioma pode revelar muito sobre as culturas. Essa decisão inicial sobre o âmbito linguístico pode ser um terreno rico para o desenvolvimento de estudos futuros que não tenham apenas o aspecto arquivístico da questão, nas quais seriam consideradas as influências sociais, econômicas e históricas, dentre outras. ${ }^{22}$ Poderíamos usar, desde o início, o idioma inglês para o cadastro, mas aí teríamos apenas um repositório com dados nivelados linguisticamente. Sem dúvida, poderia ser uma boa ideia na perspectiva de oferecer acesso mais universal facilitado, mas há outros repositórios que possuem esses objetivos. A União Europeia, por exemplo, possui a Europeana, os EUA possuem algo dentro do projeto OCLC/Worldcat, entre outros exemplos. Se, de alguma forma, a concretização do Legatum só for possível se adotarmos um idioma único para descrição, não teríamos problemas para fazê-lo, mas partimos do princípio de que os arquivos com menos recursos sempre terão mais facilidade em inserir dados em seu idioma nativo. Por outro lado, poderíamos ter dificuldades para acompanhar as inserções se elas fossem feitas

$22 \mathrm{Na}$ tese de doutoramento que vem sendo desenvolvida pelo arquivista Ricardo Sodré Andrade, Mestre em ciência da informação e um dos componentes do grupo CRIDI, vem trabalhando com o espaço lusófono como ambiente cultural e linguístico que mantém relações e diferenças entre os países que fazem parte desse escopo. Nesse espaço, Andrade considera as aproximações em meio à pluralidade das instituições arquivísticas e as ações de compartilhamento das representações de seus acervos. A ideia de um repositório de cultura latina segue a mesma linha.

\begin{tabular}{l|l|l|l|l|l|l|} 
(C) Rev. Digit.Bibliotecon. Cienc. Inf. & Campinas, SP & v.14 & n.3 & p.515-540 & set/dez. 2016 & ISSN 1678-765X \\
\hline
\end{tabular}


em farsi, japonês, vietnamita e afins, o que nos criou uma barreira neste momento em que não temos solução tecnológica ao alcance que pudesse superar esse limite. A opção pela Cultura Latina decorre da convicção de que alcançar uma parcela maior deste universo é mais fácil do que se escolhêssemos "qualquer país" como requisito à participação.

O Legatum, com o apoio institucional da esfera pública, pode proporcionar uma solução de custo tecnológico razoável e de baixo risco (embora requeira muito trabalho de convencimento junto às instituições que queremos ver utilizando o ambiente), ao mesmo tempo em que oferece elementos de reflexão teórica e prática operacional, reunindo esclarecimentos técnicos e até mesmo, acreditamos, estímulos ao engajamento também dos futuros usuários finais do ambiente. Atualmente, na Fase 3, já estamos fazendo os primeiros movimentos de adoção do sistema dedicado especificamente aos metadados de preservação.

O Legatum incorporará também o Archivematica ${ }^{23}$, um sistema (open source) de preservação digital também recomendado pelo ICA e pelo Arquivo Nacional do Brasil. Nesta ação temos o apoio fundamental da Superintendência de Tecnologia da Informação da Universidade Federal da Bahia (STI-UFBA). Consideramos também fundamental, para a reflexão e ação em torno do Legatum, bem como para sua difusão, o apoio do Arquivo Nacional, do Conselho Nacional de Arquivos (órgãos do Ministério da Justiça), da Cinemateca Brasileira (órgão do Ministério da Cultura) e do Instituto Brasileiro de Informação em Ciência e Tecnologia (IBICT, órgão do MCTI), através da Rede Brasileira de Serviços de Preservação Digital - Rede Cariniana ${ }^{24}$.

A expectativa é a de que temos que agir muito ativamente para as instituições se sensibilizarem para aderirem à proposta. Talvez esta seja uma das maiores dificuldades que estamos enfrentando, já que este tipo de ação colaborativa ainda não tem sido uma prática muito comum entre as instituições arquivísticas brasileiras, especialmente no que se refere aos acervos audiovisuais, sempre com muitas especificidades. Este talvez seja um dos mais interessantes pontos de originalidade do projeto: uma quebra de paradigma no relacionamento interinstitucional, que passa a ser remoto, podendo trazer benefícios e reunir esforços por intermédio de um grupo de pesquisa com o apoio do CNPq.

OBS.: Para a elaboração deste artigo, além dos autores/co-autores indicados junto ao título, contamos com a fundamental e efetiva colaboração de toda a equipe de bolsistas de nível superior e de iniciação científica atuantes na pesquisa, os quais também são considerados pela equipe de pesquisadores como co-autores do artigo. São eles João Ricardo Chagas dos Santos (bolsista CNPq-AT-NS1), João Victor de Amorim Pereira (bolsista de mestrado, FAPESB), Cíntia de Figueiredo Garcia (bolsista CNPq-IC), Antônio José Barreto Santos (bolsista PIBIC-UFBA-CNPq e PIBIC-UFBA-Fapesb), Illana de Brito Mascarenhas Oliveira

23 Cf. $<$ https://ww.archivematica.org/en/> .

24 Cf. <http://cariniana.ibict.br/>.

\begin{tabular}{|c|c|c|c|c|c|l|}
\hline (c) Rev. Digit.Bibliotecon. Cienc. Inf. & Campinas, SP & v.14 & n.3 & p.515-540 & set/dez. 2016 & ISSN 1678-765X \\
\hline
\end{tabular} 
(bolsista PIBIC-UFBA e PIBIC-UFBA-CNPq) e Thaise Menezes de Oliveira (bolsista PIBICUFBA e PIBIC-UFBA-CNPq).

\section{REFERÊNCIAS}

ARENDT, Hannah. Entre o passado e o futuro. São Paulo: Ed. Perspectiva, 2005.

LÉVY, Pierre. O que é o virtual? São Paulo: Editora 34, 1996.

BRUYNE, Paul de; HERMAN, Jacques; SCHOUTHEETE, Marc de. Dinâmica da pesquisa em ciências sociais: os pólos da prática metodológica. Rio de Janeiro, Francisco Alves, 1977, $252 \mathrm{p}$.

CASTELLS, Manuel. A Era da Informação: Economia, Sociedade e Cultura. v.1 A Sociedade em Rede. São Paulo: Paz e Terra, 1996.

CHAUÍ, Marilena. A universidade operacional. Folha de São Paulo, Caderno Mais!, 09maio, 1999.

D’ANGELO, Raquel Hallak.; D’ANGELO, Fernanda Hallak. Sem Fronteiras. In:

D'ANGELO, R.H.; VARGAS, Q.; D'ANGELO, F.H. (2014). CineOP - 9a Mostra de

Cinema de Ouro Preto - Cinema Patrimônio. Anais da 9 ${ }^{\mathbf{a}}$ CineOP, 28 de maio a 02 de junho de 2014, Ouro Preto (MG), 340 p., 2014, p.3-5

FRIGOTO, Gaudêncio. O enfoque da dialética materialista histórica na pesquisa educacional. In: FAZENDA, Ivani. (Org.). Metodologia da pesquisa educacional. São Paulo, Cortez, 1990, p. 69-90.

GAMBOA, Silvio. A dialética na pesquisa em educação: elementos de contexto. In:

FAZENDA, Ivani (Org.). Metodologia da pesquisa educacional. São Paulo, Cortez, 1989, p. 91-115.

HOLLÓS, Adriana Lúcia Cox.; SILVA, Rubens Ribeiro Gonçalves da. Toward a Curricular Structure / Preservação Audiovisual: Uma breve reflexão para uma estruturação curricular. ICCROM / SOIMA, 2008. Disponível em: http://soima.iccrom.org/brazil-education/ Acesso em: 15 Set. 2016.

MARCONI, Marina de Andrada; LAKATOS, Eva Maria. Fundamentos da Metodologia Científica. São Paulo, Atlas, 2003, 311 p.

MATELLART, Armand. História da Sociedade da Informação. São Paulo: Ed. Loyola, 2002 .

MENEZES, Ulpiano T. Bezerra de. Memória e cultura material: documentos pessoais no espaço público. Revista Estudos Históricos, Rio de Janeiro, v.11, n.21, 1998, p.89-103. 
SILVA, Rubens Ribeiro Gonçalves da. Arquivos audiovisuais de instituições públicas soteropolitanas: o que terá mudado, seis anos depois ? Anais do XI CINFORM - Encontro Nacional de Ensino e Pesquisa em Informação - Mundo digital: uma sociedade sem fronteira?, 19 a 21 de agosto de 2013, 2013a. Escola Politécnica/UFBA, Salvador. Disponível em: <http://www.cinform2013.ufba.br/modulos/submissao/Upload-164/49014.pdf>. Acesso em: 01 mai2015.

SILVA, Rubens Ribeiro Gonçalves da. Arquivos audiovisuais de instituições públicas soteropolitanas: retomando a pesquisa. Anais do IV SBA - Simpósio Baiano de Arquivologia, 21 a 24 de outubro de 2013, 2013b. Salvador. Disponível em:

$<$ http://www.arquivistasbahia.org/4sba/wpcontent/uploads/2014/08/Comunica\%C3\%A7\%C3\%A3o-SBA-2013-Vers\%C3\%A30Final\%C3\%ADssima.pdf>. Acesso em 01mai2015.

SILVA, Rubens Ribeiro Gonçalves da. Fundamentos, desafios e alternativas para a salvaguarda e difusão de patrimônio documental fotográfico, audiovisual e sonoro. Revista Ci. Inf., Brasília, DF, v. 40 n. 3, set./dez. 2011 [publicada somente em 2013], p.492-509, 2013c, Disponível em:

$\langle$ http://revista.ibict.br/ciinf/index.php/ciinf/article/download/2050/1450>. Acesso em: 01 mai2015.

SILVA, Rubens Ribeiro Gonçalves da. Desafios e Alternativas Digitais para a Salvaguarda e Difusão do Patrimônio Público Documental Arquivístico Audiovisual. Projeto de pesquisa aprovado pelo CNPq (bolsa de produtividade PQ2), em desenvolvimento no Grupo de Estudos sobre Cultura, Representação e Informação Digitais - CRIDI, 2012.

SILVA, Rubens Ribeiro Gonçalves da. Desafios e Alternativas Digitais para a Salvaguarda e Difusão do Patrimônio Público Documental Arquivístico Audiovisual. Slides apresentados no I SINPRED - Seminário Internacional de Preservação Digital; III Encontro Nacional da Rede cariniana. Instituto Brasileiro de Informação em Ciência e Tecnologia - IBICT, Brasília, 07 a 09 de maio de 2014, 2014a. Disponível em: http://cariniana.ibict.br/index.php/publicacoes/item/download/121_c92f08b70ebb4910fcca97 cf492cfeec . Acesso em: 28abr2015.

SILVA, Rubens Ribeiro Gonçalves da. Digitalização de acervos fotográficos públicos e seus reflexos institucionais e sociais: tecnologia e consciência no universo digital. Tese. Ciência da Informação. Orientadora: Lena Vania Ribeiro Pinheiro. Rio de Janeiro, PPGCI; UFRJ/ECO; IBICT, 2002. Disponível em: 〈http://www.cridi.ici.ufba.br/publicacoes/TeseRubens-Silva-(2002)-Digitalizacao-de-acervos-fotograficos.pdf > . Acesso: em 01mai2015.

SILVA, Rubens Ribeiro Gonçalves da. Patrimonio documental archivístico audiovisual de instituciones públicas en la ciudad de Salvador (Brasil). Revista Tendências da Pesquisa Brasileira em Ciência da Informação, João Pessoa, v.6, n.2, 2013d, p.01-14. Disponível em: http://inseer.ibict.br/ancib/index.php/tpbci/article/view/112/154 . Acesso em: 28abr2015

SILVA, Rubens Ribeiro Gonçalves da. Patrimônio documental audiovisual em arquivos de instituições públicas soteropolitanas: prosseguindo na pesquisa e expandindo-a às cidades de São Paulo, Rio de Janeiro e Belo Horizonte. Anais do IX ENECULT - Encontros de Estudos Multidisciplinares em Cultura, 11 a 13 de setembro de 2013, 2013e, Salvador (BA). 
Disponível em:

$<$ http://www.ixenecult.ufba.br/modulos/consulta\&relatorio/rel_download.asp?nome=48263.p df >. Acesso em: 01mai2015.

SILVA, Rubens Ribeiro Gonçalves da. Patrimônio documental audiovisual em instituições públicas: Desafios e alternativas. Anais do $9^{\circ}$ CineOP - Mostra e Cinema e Outro Preto / $9^{\circ}$ Encontro de Arquivos Nacionais e Acervos Audiovisuais Brasileiros, 28 de maio a 2 de junho de 2014, 2014b, Ouro Preto (MG).

SILVA, Rubens Ribeiro Gonçalves da. Retomando a pesquisa sobre patrimônio documental arquivístico audiovisual de instituições públicas. Anais do CTCM 2013 - Conferência de Cultura, Tecnologia e Memória, 12 a 14 de novembro de 2013, 2013f, Recife (PE).

SILVA, Rubens Ribeiro Gonçalves da; SZABÓ, Inácio. Informação, Ciberespaço e Consciência. Transinformação. Campinas. v. 18, n. 3, p. 191-201, set./dez., 2006.

SILVA, Rubens Ribeiro Gonçalves da; SZABÓ, Inácio. Informação e inteligência coletiva no ciberespaço: uma abordagem dialética. Ciências \& Cognição. Ano 04, v. 11, p. 37-48, 2007.

SILVA, Rubens Ribeiro Gonçalves da; SZABÓ, Inácio. Uma abordagem dialética da inteligência coletiva e da informação no ciberespaço. In: VIII Encontro Nacional de Pesquisa em Ciência da Informação (ENANCIB), Salvador, 2007. Anais... EDUFBA, ICI-UFBA, Salvador, 2007a.
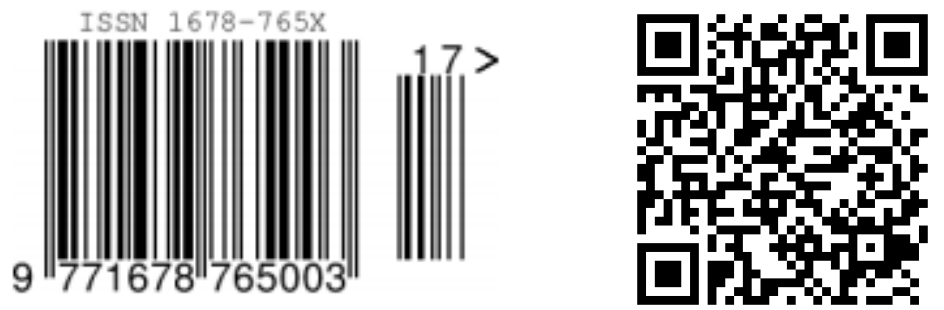